\title{
Safety design of lightweight roofs exposed to snow load
}

\author{
M. Holický \\ CTU in Prague, Klokner Institute, Prague, Czech Republic
}

\begin{abstract}
The collapse of a number of lightweight roofs during the winter period of $2005 / 2006$ initiated an international discussion concerning the reliability of roofs exposed to permanent snow load. In some countries, all available measurements of snow loads have been newly evaluated and relevant standards have been promptly revised. Newly developed maps of snow loads are based on the principles of the European standards specifying the characteristic value of snow load on the ground as the 98 fractile of annual extremes ( 50 year return period). This paper provides a critical analysis of presently accepted design procedures taking into account available data of snow load. In the reliability analysis permanent load is described by normal distribution, snow load by Gumbel distribution and resistance by lognormal distribution. It appears that the partial factor design method provided in the present European standards may not guarantee an adequate reliability level of lightweight roofs. An alternative procedure for the safety design of roofs exposed to self weight and snow load only is therefore proposed.
\end{abstract}

Keywords: lightweight roofs, snow load, safety, design.

\section{Introduction}

The reliability of lightweight roofs has become an important topic of structural design, particularly after the winter period 2005/2006 when a number of roofs in Europe collapsed. In some countries, available measurements of snow loads have been newly evaluated and relevant standards have been promptly revised. Newly developed maps of snow loads take into account the principles of valid European standards [1-3] specifying the characteristic value of snow load on the ground as the 98 fractile of annual extremes. The design value of snow load is then determined using the partial factor 1,5 . 
This paper provides a critical analysis of presently accepted design procedures taking into account available measurements. Normal distribution for permanent load, Gumbel distribution for snow load and lognormal distribution for resistance are assumed in the reliability analysis [4,5]. The presented study is an extension of the recent paper [6] and confirms its conclusion that available European standards may not guarantee an adequate reliability level for lightweight roofs. An alternative procedure of the safety design of lightweight roofs exposed to permanent and snow load only is, therefore, proposed.

\section{Partial factor design}

In accordance with the principles of the present suite of European standards (Eurocodes) the characteristic value of the snow load on the ground $s_{k}$ is specified as the 0,98 fractile of annual extremes (50 years' return period) [1,2] assuming the Gumbel distribution. The characteristic load on the roof is then determined as

$$
s_{s, k}=\mu C_{\mathrm{e}} C_{\mathrm{t}} s_{k}
$$

where $\mu$ denotes the shape factor (for horizontal roofs equal to 0,8 ). $C_{\mathrm{e}}$ and $C_{\mathrm{t}}$ denote the exposure and thermal factors considered usually as unity [3] (and omitted further on). In the design of a structural component exposed to the permanent load $G$ and snow load $S$, the value of a generic resistance $R$ is determined using the partial factor method and the fundamental load combination [1] as

$$
R_{\mathrm{k}} / \gamma_{\mathrm{M}}=\gamma_{G} G_{\mathrm{k}}+\gamma_{Q} s_{\mathrm{s}, \mathrm{k}}
$$

Here $R_{\mathrm{k}}$ denotes the characteristic resistance $(0,05$ fractile $), \gamma_{\mathrm{M}}$ the resistance partial factor (considered by a generic value 1,15), $\gamma_{G}$ the partial factor of permanent load (considered by a recommended value 1,35), $G_{\mathrm{k}}$ the characteristic value of the permanent load (the mean of $G$ ), $\gamma_{Q}$ the partial factor of the snow load (considered by a recommended value 1,5). Note that equation (2) corresponds to the fundamental load combination given in EN 1990 [1] by expression (6.10). The other (more economic) load combinations provided in [1] are not considered here but may be treated in a similar way.

\section{Basic variables of reliability analysis}

The reliability analysis of a structural member exposed to a permanent load $G$ and snow load $S$ is, based on the limit state function $g(X)$, given as

$$
\mathrm{g}(\boldsymbol{X})=K_{\mathrm{R}} R-K_{\mathrm{E}}\left(G+S_{50}\right)
$$

The basic variables $\boldsymbol{X}$, entering equation (3), are described in Table 1. In accordance with EN 1990, the design life time of 50 years is considered and, therefore, the 50 years' extreme $S_{50}$ of the snow load $s_{\mathrm{s}, \mathrm{k}}$ on the roof (considering 
the shape factor $\mu=0,8$ ) is assumed in equation (3). Note that the statistical characteristics given in Table 1 are derived taking into account the principles of Eurocodes [1-3].

In the following analysis, the load ratio $\chi$ is given as a fraction of the characteristic value of the snow load $s_{\mathrm{s}, \mathrm{k}}$ and the total load $G_{\mathrm{k}}+s_{\mathrm{s}, \mathrm{k}}$

$$
\chi=s_{\mathrm{s}, \mathrm{k}} /\left(G_{\mathrm{k}}+s_{\mathrm{s}, \mathrm{k}}\right)
$$

The load ratio $\chi$ for lightweight roofs is expected within the interval from 0,4 to 0,8 . For a given $\chi$ and $s_{\mathrm{s}, \mathrm{k}}$ the characteristic permanent load follows from equation (4) as

$$
G_{\mathrm{k}}=s_{\mathrm{s}, \mathrm{k}}(1-\chi) / \chi
$$

The characteristic value $s_{\mathrm{s}, \mathrm{k}}$ is considered by the normalized value 1 (say 1 $\mathrm{kN} / \mathrm{m}^{2}$ ). The mean of $S_{50}$ is approximately equal to the characteristic value $S_{\mathrm{s}, \mathrm{k}}$ (see Table 1).

Alternatively, the partial factor of snow load $\gamma_{Q}$ is proposed as a quantity dependent on the load ratio $\chi$ (similarly as suggested in recent studies $[7,8]$ for the partial factor of variable actions)

$$
\gamma_{Q}=1+\chi
$$

It appears that the partial factor $\gamma_{Q}$ given by equation (6) leads to a more uniform reliability level than the constant value $\gamma_{Q}=1,5$.

The theoretical models of basic variables indicated in Table 1 are based on recommendations of JCSS (Joint Committee on Structural Safety) [5] and previous studies [6-8].

Table 1: $\quad$ Models of basic variables.

\begin{tabular}{|l|c|c|c|c|c|c|}
\hline Variable & $\begin{array}{c}\text { Symb. } \\
X\end{array}$ & Distr. & $\begin{array}{c}\text { Partial } \\
\text { factor } \gamma\end{array}$ & $\begin{array}{c}\text { Char. val. } \\
X_{\mathrm{k}}\end{array}$ & $\begin{array}{c}\text { The mean } \\
\mu_{X}\end{array}$ & $\begin{array}{c}\mathrm{CoV} \\
V_{X}\end{array}$ \\
\hline Resistance & $R$ & $\mathrm{LN}$ & 1,15 & From $(2)$ & $1,25 R_{\mathrm{k}}$ & 0,10 \\
\hline Permanent load & $G$ & $\mathrm{~N}$ & 1,35 & From $(5)$ & $1,0 G_{\mathrm{k}}$ & 0,10 \\
\hline $\begin{array}{l}\text { Snow load, 50- } \\
\text { years maximum }\end{array}$ & $S_{50}$ & $\mathrm{GU}$ & $\gamma_{Q}$ & $s_{s, \mathrm{k}}$ & $1,0 s_{s, \mathrm{k}}$ & 0,22 \\
\hline Resistance uncert. & $K_{R}$ & $\mathrm{~N}$ & - & - & 1,0 & 0,05 \\
\hline Load effect uncert. & $K_{E}$ & $\mathrm{~N}$ & - & - & 1,0 & 0,10 \\
\hline
\end{tabular}

In Table 1 the symbol "N" denotes normal distribution, "LN" lognormal distribution with the lower bound at the origin and "GU" Gumbel distribution of maximum values. The partial factor $\gamma_{Q}$ applied to the characteristic snow load $s_{s, \mathrm{k}}$ equals 1,50 or alternatively $1+\chi$, as indicated in equation (6). 


\section{Results of reliability analysis}

Results of the reliability analysis are indicated in Figures 1 and 2. Figure 1 shows the variation of the reliability index $\beta$ with the load ratio $\chi$ for the fundamental load combination applied in equation (2) and two different partial factors $\gamma_{Q}$ : the constant factor $\gamma_{Q}=1,5$ (recommended value) and a variable one $\gamma_{Q}=1+\chi$.

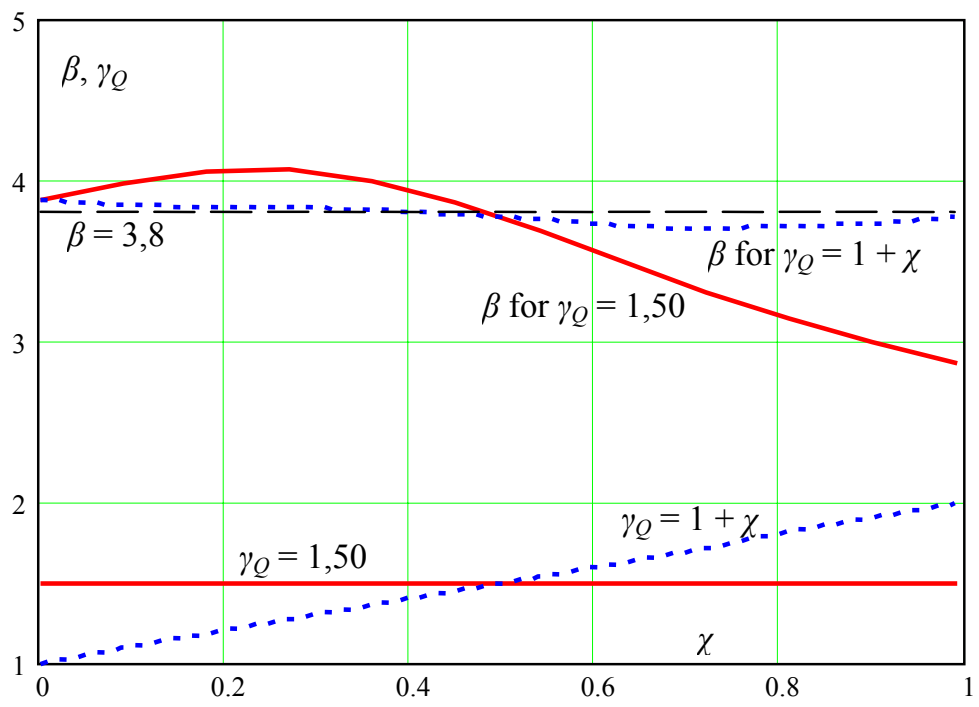

Figure 1: $\quad$ Variation of the reliability index $\beta$ with the load ratio $\chi$ for the partial factors $\gamma_{Q}=1,5$ and $\gamma_{Q}=1+\chi$.

It follows from Figure 1 that the constant partial factor $\gamma_{Q}=1,5$ leads to a significant variation of the reliability index with the load ratio $\chi$. Moreover, for the load ratios $\chi>0,5$ the index decreases below the target value of 3,8 recommended in [1] and the reliability of a structural member is insufficient. The partial factor $\gamma_{Q}=1,5$ seems to be satisfactory for the load ratio $\chi<0,5$ only. For the ratio $\chi>0,5$ the partial factor for snow load $\gamma_{Q}$ should be greater than 1,5 . Obviously, a significantly more uniform reliability level is obtained for the partial factor $\gamma_{Q}=1+\chi$, which seems to lead to an acceptable reliability level for any load ratio $\chi$.

The results indicated in Figure 1 are confirmed by Figure 2 showing the variation of the reliability index $\beta$ with the partial factor $\gamma_{Q}$ (within the range from 1,2 to 2 ) for selected load ratios $\chi=0,4,0,6$ and 0,8. Apparently, to reach the desired reliability index $\beta=3,8$ the partial factor $\gamma_{Q}$ should increase with an increasing load ratio $\chi$. For a realistic load ratio $\chi=0,6$ (an expected value for lightweight roofs) the partial factor $\gamma_{Q}$ should be about 1,6, thus $\gamma_{Q}=1+\chi$. Similar results are indicated in a recent study [9]. 


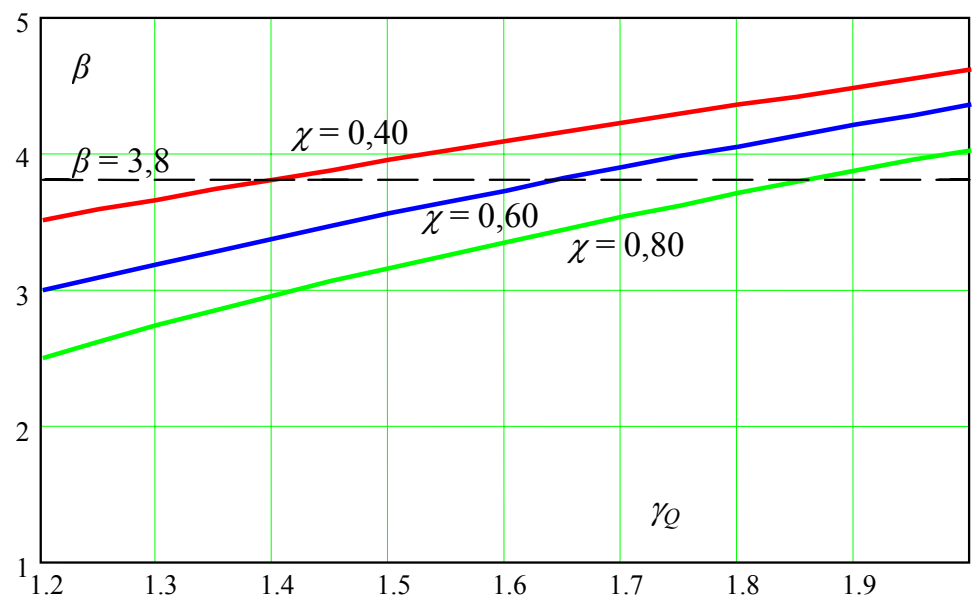

Figure 2: $\quad$ Variation of the reliability index $\beta$ with the partial factor $\gamma_{Q}$ for the selected load ratios $\chi=0,4,0,6$ and 0,8 .

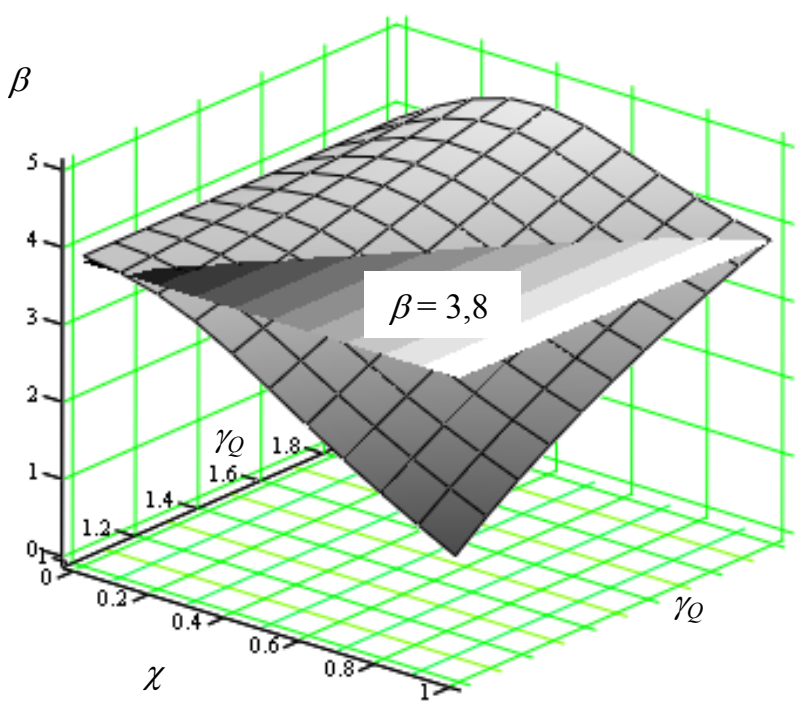

Figure 3: $\quad$ Variation of the reliability index $\beta$ with the load ratio $\chi$ and the partial factor $\gamma_{Q}$. 
Figure 3 shows the variation of the reliability index $\beta$ with both the load ratio $\chi$ and the partial factor $\gamma_{Q}$. It can be used for the specification of the adequate partial factor $\gamma_{Q}$ for a given load ratio $\chi$, so that the desired reliability level $\beta=$ 3,8 would be guaranteed. Figure 3 also clearly shows why the partial factor $\gamma_{Q}$ should depend on the load ratio $\chi$ (as indicated by equation (6)) if a uniform reliability level (a constant index $\beta$ ) is to be achieved.

\section{Concluding remarks}

The following conclusions may be drawn from the presented study:

1. The constant partial factor $\gamma_{Q}=1,5$ leads to a significantly variable (nonuniform) reliability level with respect to the load ratio $\chi$.

2. For the load ratios $\chi>0,5$ the index $\beta$ is less than 3,8 and reliability of a structural member is insufficient.

3. The recommended partial factor $\gamma_{Q}=1,5$ seems to be satisfactory for a load ratio $\chi<0,5$. For a ratio $\chi>0,5$ the partial factor for snow load $\gamma_{Q}$ should be greater than 1,5 .

4. To reach the desired reliability index $\beta=3,8$ the partial factor $\gamma_{Q}$ should increase with an increasing load ratio $\chi$.

5. A significantly more uniform reliability level is obtained for the partial factor $\gamma_{Q}=1+\chi$, which seems to lead to an acceptable reliability level for any load ratio $\chi$.

It is, however, emphasized that the presented results may be significantly dependent on the assumed models for basic variables and should be considered as informative only.

\section{Acknowledgement}

This study is a part of the project GACR 103/06/1521 "Reliability and risk assessment of structures in extreme conditions".

\section{References}

[1] EN 1990 Eurocode: Basis of structural design. CEN, 2002.

[2] EN 1991-1-1 Actions on structures - Part 1-1: General actions Densities, self weight, imposed loads for buildings. CEN, 2002.

[3] EN 1991-1-3 Eurocode 1: Actions on Structures - Part 1-3: General actions - Snow loads. CEN, 2004.

[4] Commission of the European Communities, DGIII-D3, Snow loads, Final Report, University of Pisa, 1999.

[5] JCSS Probabilistic Model Code, http://www.jcss.ethz.ch/, 2005.

[6] Holický M., Marková J. and Sýkora M.: Spolehlivost lehkých střech (Reliability of lightweight roofs), Stavební obzor 2007 (to be published).

[7] Holický, M. - Retief, J.: Reliability Assessment of Alternative Eurocode and South African Load Combination Schemes for Structural Design. 
Journal of the South African Institution of Civil Engineering. 2005, vol. 47, no. 1, p. 15-20.

[8] Holický, M. Calibration of load combinations for equal safety of concrete members In: Proceedings of the $6^{\text {th }}$ International Congress Global Construction: Ultimate Concrete Opportunities, 5-7 July 2005, Dundee UK, pp. 677-684.

[9] Schleich J.B., Sedlacek G. \& Kraus O. Realistic Safety Approach for Steel Structures, In: Eurosteel, Coimbra, p. 1521-1530, 2002. 